\title{
Risk factors of chronic noncommunicable diseases comorbidity in South- Kazakhstan region
}

\author{
Saule Urazalina, Aisulu Mussagalieva, Assel Issabekova, Kulzida Koshumbaeva, Bagdat Akhit
}

Cardiology Unit, Postgraduate Education Department, Scientific-Research Institute of Cardiology and Internal Diseases, Almaty, Republic of Kazakhstan
This work is licensed under a Creative Commons Attribution 4.0 International License

\section{Received: 2019-01-10}

Accepted: 2019-03-14

UDC: 616.1

\section{J Clin Med Kaz 2019;1(51):50-55}

Corresponding Author: Saule Urazalina, MD, PhD, Professor at the Cardiology Unit, Postgraduate Education Department, Scientific-Research Institute of Cardiology and Internal Diseases, Almaty, Republic of Kazakhstan. Tel.: 87772446090

E-mail: surazalina@mail.ru

\section{Abstract}

Aim: To conduct a one-stage multicenter study in South-Kazakhstan Region to obtain baseline prevalence of comorbidity of chronic noninfectious diseases and their risk factors.

Material and methods: 1400 persons at the age of 18-69, living in the South-Kazakhstan region. Epidemiological part consisted of: interviewing, physical examination and laboratory tests. For statistical analysis were used MSAccess and SPSS22.0. computer programs.

Results: $12.7 \%$ of respondents in South-Kazakhstan region smoke, which statistically significantly less than number of nonsmoking $(87.3 \% ; \mathrm{p}<0.01)$ ones. The number of alcohol drinkers is $28.4 \%$, which also less than number of nondrinkers $(71.6 \% ; \mathrm{p}<0.01)$. The $48.3 \%$ of people included in the study had physical inactivity, while $51.7 \%$ had sufficient physical activity.

More than half of respondents had abdominal obesity $(67.9 \%)$, which higher than number of people without obesity $(32.1 \% ; p<0.01)$. The $72.1 \%$ had chronic noninfectious diseases (1009 of 1400). Comorbidity with two diseases $48.2 \%$ (676 of 1400). Most common disease was arterial hypertension (45.9\%: 464 of 1009). Less common - chronic kidney disease (2.4\%:24 of 1009). The most common comorbidity - arterial hypertension and diabetes mellitus (72.3\%). The less common - obesity and chronic obstructive pulmonary diseases $(2.3 \%)$.

Conclusions: 1 . The most common risk factors of chronic noninfectious diseases in South-Kazakhstan region are improper diet, obesity, physical inactivity.

2. The frequency of chronic noninfectious diseases in South-Kazakhstan region was $72.1 \%$. And the most common disease was arterial hypertension.

3 . The most common comorbidity - combination diabetes mellitus with arterial hypertension while the less common - combination obesity with chronic obstructive pulmonary disease. diseases

Key words: comorbidity, epidemiology, risk factors, chronic noninfectious

\section{ОНТУСТІК ҚАЗАҚСТАН ОБЛЫСЫ БОЙЫНША ИНФЕКЦИЯЛЫҚ ЕМЕС СОЗЫЛМАЛЫ АУРУЛАРДЫН КОМОРБИДТІК ҚАУІПТІЛІК ФАКТОРЛАРЫ}

С.Ж. Уразалина, А.Т. Мусагалиева, А.Х. Исабекова, К.М. Кошумбаева, Б. Ахыт

Кардиология кафедрасы, Жоғары оку орнынан кейінгі департаменті, Кардиология және ішкі аурулар ғылыми-зерттеу орталығы, Алматы, Қазақстан Республикасы

\section{ТҰЖЫРЫМДАМА}

Зерттеу мақсаты: Негізгі инфекциялық емес созылмалы аурулардың таралуының қауіптілік фракторларының бастапқы көрсеткіштеріне ие болу үшін Оңтүстік Қазақстан облысында бір реттік зерттеу жүргізу.

Материал мен әдістер: Оңтүстік Қазақстан облысында тұратын, 18-69 жас аралығындағы 1400 адам. Зерттеудің эпидемиологиялық бөлігі үш кезеңнен тұрады: сұхбатнама жүргізу, физикалық зерттеу, зертханалық зерттеу жүргізу. Алынған нәтижелер МS Ассеss компьтерлік бағдарламасына енгізіліп, өңдеу жүргізу мен анализ SPSS 22.0. бағдарламасында жасалды.

Нәтижелер: Жалпы алғанда Оңтүстік Қазақстан облысында тұратын респонденттердің 12.7\% темекі тартады, бұл темекі тартпайтын тұлғаларға қарағанда статистикалық жағынан айтарлықтай аз (87.3\%: p<0.01) болып табылады. Зерттеу жүргізілген тұлғалардың 28.4\% 
ішімдік ішеді, бұл көрсеткіш ішімдік ішпейтін тұлғалармен салыстырғанда (71.6\%: р<0.01) едәуір аз болып табылады. Респонденттердің жартысынан басым көпшілігі (48.3\%) аз қимылдайтын өмір салтын ұстанады. Абдоминалдық семіздікке ұшырағандар саны 67.9\% құрайды, бұл көрсеткіш абдоминалдық семіздікке ұшырамағандар санымен салыстырғанда (32.1\%: р<0.01) бірталай жоғары болып саналады.

Зерттеу жүргізілген топтың жалпы алғанда 72.1\% пациентінде инфекциялық емес созылмалы аурулардың (1400 адамның 1009-ы) бар екендігі анықталды. Бұл ретте ИЕСА бойынша 48.2\% пайызы (1400 адамның 676-сы) коморбидтік факторға ұшыраған. Ең көп таралған аурулар түріне артериялдық гипертония (45.9\%: 1009-дың 464-і ИЕСА) жатады. Ең аз таралған аурулар тобына созылмалы бауыр аурулар (2.4\%: 1009-дың 24-і) жатады. Ең жиі кездесетін коморбидтік жай-күйге қант диабет мен артериялдық гипертония қосындысы (72.3\%) жатады. Ең жиі кездесетіні - созылмалы обструқтив өкпе аурулар мен семіздігі (2.3\%).

Қорытындылар: 1. Оңтүстік Қазақстан облысында инфекциялық емес созылмалы аурулардың зерттеуге алынған тұлғалар арасында ең көп таралған қауіптілік факторлары - дұрыс тамақтанбау (жеміс-жидектерді жеткіліксіз пайдалану), семіздік, гипердинамия жатады.

2. Оңтүстік Қазақстан облысында инфекциялық емес созылмалы аурулардың $72.1 \%$ құрайды; бұл ретте ең көп таралған ауру түрі артериялық гипертония болып табылады.

3. Екі инфекциялық емес созылмалы аурулардың бойынша ең жиі кездесетін коморбидтік жай-күйге - артериялық гипертония мен қант диабет қосындысы жатады, ең аз таралған қосынды - созылмалы обструқтив өкпе аурулар мен бірге семіздік.

Негізгі сөздер: эпидемиология, қауіптілік факторлары, созылмалы инфекциялық емес аурулар

\section{ФАКТОРЫ РИСКА КОМОРБИДНОСТИ ХРОНИЧЕСКИХ НЕИНФЕКЦИОННЫХ ЗАБОЛЕВАНИЙ В ЮЖНО- \\ КАЗАХСТАНСКОЙ ОБЛАСТИ}

С.Ж. Уразалина, А.Т. Мусагалиева, А.Х. Исабекова, К.М. Кошумбаева, Б. Ахыт

Кафедра кардиологии, Департамент последипломного образования, Научно-исследовательский институт кардиологии и внутренних болезней, Алматы, Республика Казахстан

\section{РЕЗЮМЕ}

Цель: Провести одномоментное исследование в Южно-Казахстанской области для получения исходных показателей распространенности фракторов риска коморбидности основных хронических неинфекционных заболеваний.

Материал и методы: 1400 человек в возрасте 18-69 лет, проживающие в Южно-Казахстанской области. Эпидемиологическая часть исследования проводилась в три этапа: интервьюирование, физикальное обследование, лабораторный. Полученные результаты введены в компьютерную программу MS Access, обработка и анализ были проведены в SPSS 22.0.

Результаты: В Южно-Казахстанской области в целом курит 12.7\% респондентов, что статистически значимо меньше некурящих лиц (87.3\%: р<0.01). Алкоголь употребляли 28.4\% включенных в исследование лиц, что достоверно ниже количества лиц, употреблявших алкоголь (71.6\%: p<0.01). Половина респондентов (48.3\%) вели малоподвижный образ жизни. Абдоминальное ожирение выявлено у $67.9 \%$ лиц, что значимо выше, чем количество лиц без абдоминального ожирения (32.1\%: p<0.01). В обследованной группе хронические неинфекционные заболевания в целом выявлялись у 72.1\% пациентов (1009 из 1400). При этом 48.2\% из них имели коморбидность по двум ХНИЗ (676 из 1400). Наиболее распространенным заболеванием была артериальная гипертензия (45.9\%: 464 из 1009 с ХНИ3). Наименее распространенным хронические болезни почек (2.4\%: 24 из 1009 с ХНИЗ). Наиболее частым коморбидным состоянием являлось сочетание сахарного диабета и артериальной гипертензии (72.3\%). Наименее частым - ожирение с хроническими обструктивными болезнями легких (2.3\%).

Выводы: 1. Наиболее распространенными факторами риска хронических неинфекционных заболеваний среди лиц, включенных в исследование в Южно-Казахстанской области, являлись неправильное питание (недостаточное употребление овощей и фруктов), ожирение, гиподинамия.

2. Частота встречаемости хронических неинфекционных заболеваний в целом по Южно-Казахстанской области составила 72.1\%; при этом самым распространенным заболеванием была артериальная гипертензия.

3. Наиболее часто встречающееся коморбидное состояние по двум ХНИЗ - сочетание сахарного диабета и артериальной гипертензии, наименее встречающееся сочетание - ожирение с хроническими болезнями легких.

Ключевые слова: эпидемиология, коморбидность, фракторы риска, хронические неинфекционные заболевания

\section{Введение}

Хронические неинфекционные заболевания (ХНИЗ) группа заболеваний, выделяемых Всемирной организацией здравоохранения (ВО3), к которой относят болезни системы кровообращения (БСК), болезни органов дыхания, пищеварительной системы, почек, ревматологические, эндокринологические заболевания, в первую очередь сахарный диабет [1-3]. ХНИЗ являются основной причиной заболеваемости, инвалидности и смертности (в том числе преждевременной) в Казахстане [4,5].

Высокая заболеваемость и смертность при ХНИЗ, значительные социально-экономические последствия этой ситуации для развития страны обуславливают необходимость укрепления потенциала системы здравоохранения для эффективного реагирования на растущее бремя ХНИЗ $[5,6]$. В Республике Казахстан (РК) в этом направлении достигнут определенный прогресс, имеется также прочная политическая приверженность, однако, вопросы контроля за ХНИЗ все еще нуждаются в улучшении. Особого внимания для улучшения качества услуг здравоохранения требует все возрастающая распространенность коморбидных состояний в мире, о чем свидетельствуют многочисленные эпидемиологические исследования во многих странах, посвященных данной теме $[7,8]$. При этом проблема выявления факторов риска (ФР) коморбидности является чрезвычайно актуальной как для врачей общей практики, семейных врачей, так и кардиологов [7-9].

\section{Цель исследования}

Провести одномоментное исследование в ЮжноКазахстанской области (ЮКО) для получения исходных показателей распространенности факторов риска коморбидности основных ХНИЗ.

\section{Материал и методы}

В исследовании приняли участие 1400 человек в возрасте 18-69 лет, проживающие ЮКО.

Критерии включения в исследование: лица любой национальности в возрасте 18-69 лет, являющиеся гражданами РК и проживающие в ЮКО 5 и более лет.

Критерии исключения: лица, не являющиеся гражданами РК, а также проживающие в исследуемых регионах менее 5 лет.

Исследование состояло из аналитического, эпидемиологического частей. Эпидемиологическая часть исследования (сквозное, кросс-секционное) проводилась в три этапа: интервьюирование, физикальное обследование, лабораторное исследование. В качестве кластеров (первичных единиц отбора) выступили терапевтические участки. Отбор респондентов производился на основе списка прикрепленного населения с использованием систематической (шаговой) выборки. На первом этапе сбора данных респондент проходил интервью по анкете, которая была направлена на получение информации социально-демографического характера, о поведенческих и биомедицинских факторах 
риска и распространенности основных ХНИЗ (артериальная гипертензия, сахарный диабет, хроническая обструктивная болезнь легких, анемии, хроническая болезнь почек). Всем респондентам проводилось физикальное обследование (рост, вес, окружность талии, обхват бедер, индекс массы тела, трехкратное измерение артериального давления на обеих руках по методу Короткова, оценка функции внешнего дыхания методом пикфлоуметрии).

Лабораторное исследование включало: 1. Общий анализ крови и мочи. 2. Биохимический анализ крови: глюкоза (норма <6.0 ммоль/л); гликированный гемоглобин (HbA1C, норма=4.0-6.0\%); креатинин (норма: ж=44.0-80.0; м=74.0-110.0 мкмоль/л); витамин В12 (норма=180-900 пг/ мл); фолиевая кислота (норма=3-17 нг/мл); ферритин (норма: м=20-300; ж-10-120 нг/мл). 3. Показатели липидного спектра: общий холестерин (ОХС, норма $\leq 5.0$ ммоль/л), ХС-ЛПНП (норма $\leq 3.0 \mathrm{ммоль/л),} \mathrm{ХС-ЛПВП} \mathrm{(норма:} \mathrm{м>1.0ммоль/л;}$ ж>1.2ммоль/л), триглицериды (ТГ, норма $\leq 1.7$ ммоль/л). Применялся ARCHitect c Systems 8000, гомогенный метод.

Факторы риска ХНИЗ определялись в соответствии со стандартизированной методикой BO3 STEPS [2]

\section{Статистический анализ}

При помощи программы MS Access была сформирована исследовательская база данных. Ее обработка и анализ были проведены в SPSS 22.0. Стандартизированные показатели заболеваемости рассчитывались методом прямой стандартизации согласно методическому руководству Агентства по статистике РК [10]:

$$
K^{\text {станд }}=\sum t_{x} \times P_{x}^{\text {станд }}, t_{x}=\frac{S_{x}}{P_{x}}, \text { где }
$$

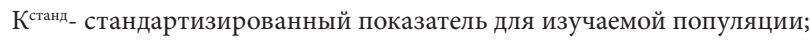
$\mathrm{t}^{\mathrm{x}}$ - возрастные показатели смертности в изучаемой популяции; P_х^станд - долисоответствующих возрастных групп в структуре населения, принятого за стандарт;

$\mathrm{P}^{\mathrm{x}}$-среднегодовая численность населения в возрастной группе $\mathrm{x}$ в изучаемой популяции;

$\mathrm{S}^{\mathrm{x}}$ - число событий в возрастной группе $\mathrm{x}$ в изучаемой популяции.

\section{Результаты}

В ходе рандомизации в исследование включено 1400 человек: мужчин - 31.6\%; женщин - 68.4\%. Обобщенная социально-демографическая характеристика респондентов представлена в Таблице 1 .

В ходе исследования был проведен анализ общепризнанных поведенческих факторов риска таких как: курение, чрезмерное употребление алкоголя, недостаточная физическая активность и неправильное питание [11,12]. Результат представлен в Таблице 2.

Таблица 1 Социально-демографическая характеристика респондентов $(\mathrm{n}=1400)$

\begin{tabular}{|c|c|c|}
\hline \multicolumn{2}{|l|}{ Параметры } & Количество (\%) \\
\hline \multirow[t]{5}{*}{ Возраст } & $18-24$ & $11.0^{*}$ \\
\hline & $25-39$ & 24.9 \\
\hline & $40-49$ & 23.7 \\
\hline & $50-59$ & 24.9 \\
\hline & $60-69$ & 15.6 \\
\hline \multirow[t]{2}{*}{ Тип поселения } & город & $45.3^{*}$ \\
\hline & село & 54.7 \\
\hline \multirow[t]{3}{*}{ Образование } & высшее & 29.2 \\
\hline & среднее & $56.9 * *$ \\
\hline & неполное среднее & 13.9 \\
\hline \multirow[t]{2}{*}{ Национальность } & азиатская & $91.1^{* *}$ \\
\hline & европейская & 8.9 \\
\hline \multirow[t]{5}{*}{ Род занятий } & работающие & $49.8^{* *}$ \\
\hline & учащиеся & 3.2 \\
\hline & домохозяйки & 17.1 \\
\hline & пенсионеры & 16.7 \\
\hline & безработные & 13.2 \\
\hline
\end{tabular}

* Отличия с значениями, средними по выборке, статистически значимы по 2 -х стороннему точному критерию Фишера $(\mathrm{p}<0.05)$;

** Отличия с значениями, средними по выборке, статистически значимы $(\mathrm{p}<0.01)$.

Таблица 2 Характеристика респондентов (n=1400) по поведенческим факторам риска

\begin{tabular}{|l|l|l|l|l|}
\hline Кораметры & Курение & $\begin{array}{l}\text { Употребление алкоголя в } \\
\text { течение 12 месяцев }\end{array}$ & $\begin{array}{l}\text { Употребление 5 и более } \\
\text { порций овощей и фруктов } \\
\text { ежедневно }\end{array}$ & $\begin{array}{l}\text { Малоподвижный образ жизни } \\
\text { (менее 600 минут в неделю) }\end{array}$ \\
\hline Да (\%) & 12.7 & 28.4 & 47.2 & 48.3 \\
\hline Нет (\%) & $87.3^{* *}$ & $71.6^{* *}$ & 52.8 & 51.7 \\
\hline
\end{tabular}

* Отличия с значениями, средними по выборке, статистически значимы по 2-х стороннему точному критерию Фишера ( $<0.05)$;

** Отличия с значениями, средними по выборке, статистически значимы $(\mathrm{p}<0.01)$.

В результате проведенного анкетирования установлено, что в Южно-Казахстанской области (ЮКО) в целом курит $12.7 \%$ респондентов, что статистически значимо меньше, чем некурящих лиц (87.3\%: $<<0.01)$. Алкоголь употребляли $28.4 \%$ включенных в исследование лиц, что также достоверно ниже, чем лиц, не употреблявших алкоголь (71.6\%: $<<0.01)$. Известно, что характер питания, в частности недостаточное потребление овощей и фруктов, является значимым фактором риска, оказывающим влияние на развитие ХНИЗ [11-13]. Около половины обследованных лиц в ЮКО (47.2\%) ежедневно употребляли овощи и фрукты в достаточном количестве, что статистически значимо не различалось с количеством лиц недостаточно их употреблявшим $(52.8 \%$ : $\mathrm{p}>0.05)$.

Гиподинамия - одна из важных проблем в современном мире $[1,11]$. В целом по региону почти половина респондентов $(48.3 \%)$ вели малоподвижный образ жизни. В то время как $51.7 \%$ лиц имели достаточную физическую активность ( $>>0.05)$. Понятие «малоподвижный образ жизни» означало наличие физической активности (ходьбы, бега, тренировок в тренажерном зале или специальных спортивных упражнений) менее 600 минут в неделю.

Таким образом, самыми распространенными поведенческими факторами риска в ЮКО были неправильное питание (52.8\%) и гиподинамия (51.7\%).

К числу основных биомедицинских факторов риска, повышающих вероятность большинства ХНИЗ, относятся: избыточная масса тела, повышенный уровень кровяного давления, гипергликемия и дислипидемия [11-13]. Результаты по региону представлены в Таблице 3 . 
Таблица 3 Распространенность биомедицинских факторов риска среди респондентов (n=1400)

\begin{tabular}{|c|c|c|c|c|c|c|c|c|}
\hline Количество & $\begin{array}{l}\text { ИМТ } \\
\geq 30\end{array}$ & $\begin{array}{l}\text { OT, сM } \\
(\mathrm{M}>102 ; \\
\text { Ж>88) }\end{array}$ & $\begin{array}{l}\text { ОХС >5.0 } \\
\text { ммоль/л }\end{array}$ & $\begin{array}{l}\text { ХС-лПВП, } \\
\text { ммоль/л } \\
\text { (м<1.03; } \\
\text { ж<1.29) }\end{array}$ & $\begin{array}{l}\text { ХС-лПнП } \\
>3.0 \\
\text { ммоль/л }\end{array}$ & $\begin{array}{l}\text { ТГ }>1.7 \\
\text { ммоль/л }\end{array}$ & $\begin{array}{l}\text { Глюкоза } \\
\text { крови >5.6 } \\
\text { ммоль/л }\end{array}$ & $\mathrm{A} \Gamma$ \\
\hline Да (\%) & $61.5^{*}$ & $67.9^{*}$ & 13.2 & $69.0^{*}$ & 18.4 & 21.5 & 8.6 & 22.4 \\
\hline Нет (\%) & 38.5 & 32.1 & $86.8^{*}$ & 31.0 & $81.6^{* *}$ & $78.5^{* *}$ & $91.4^{* *}$ & $77.6^{*}$ \\
\hline
\end{tabular}

ИМТ - индекс массы тела; ОТ - окружность талии; ОХС - общий холестерин; ТГ -триглецириды; АГ -артериальная гипертензия

В целом в ЮКО более половины обследованных лиц страдали ожирением (ИМТ $\geq 30)(61.5 \%)$, что статистически значимо больше количества лиц без ожирения $(\mathrm{p}<0.01)$. Одним из важных факторов риска развития БСК является наличие абдоминального ожирения (АО), которое оценивалось по увеличенной окружности талии (ОТ): у мужчин $>102 \mathrm{~cm}$, у женщин $>88 \mathrm{~cm}$ [13-15]. В нашем исследовании АО выявлено у $67.9 \%$ лиц, что также значимо выше, чем количество лиц без АО (32.1\%: $\mathrm{p}<0.01)$.

В ходе исследования нами проанализированыпоказатели липидного спектра крови. Повышенный уровень общего холестерина крови (ОХC) натощак отмечен всего у 13.2\% лиц, что достоверно ниже, чем у лиц, у которых ОХС был в норме $(86.8 \%$ : $\mathbf{p}<0.01)$. Аналогичная картина имела место и в отношении распространенности повышенного уровня ХCЛПНП: только у $18.4 \%$ против $81.6 \%$ без повышенного его уровня $(\mathrm{p}<0.01)$. Около четверти всех респондентов страдали гипертриглицеридемией $(21.5 \%)$, что значимо ниже числа лиц с увеличенным его значением (78.5\%: $\mathbf{p}<0.01)$. Повышенный уровень глюкозы крови натощак имело небольшое количество лиц $(8.6 \%$ против $91.4 \%$ : $<<0.01)$.
Одним из важнейших модифицируемых факторов риска развития ХНИЗ является повышенный уровень артериального давления (АД) [15-17]. Частота встречаемости повышенного АД (140/90 мм рт.ст. и выше.), по результатам измерений, проведенных во время включения в исследование, составила $22.4 \%$. Следует отметить, что данный показатель указывает на распространенность неконтролируемой артериальной гипертензии (АГ).

Таким образом, в ЮКО наиболее распространенным биомедицинскими факторами риска было ожирение (67.9\%).

В ходе эпидемиологического исследования проведен анализ частоты встречаемости у одного пациента таких наиболее распространенных ХНИЗ, как АГ, сахарный диабет (СД), хроническая болезнь почек (ХБП), анемия, ожирение. Установлено, что в обследованной группе ХНИЗ в целом выявлялись у 72.1\% пациентов (1009 из 1400). При этом $48.2 \%$ из них имели коморбидность по двум ХНИЗ (676 из 1400). Нами проанализирована частота встречаемости коморбидности по двум ХНИЗ в изучаемом регионе. Результаты приведены в Таблице 4 .

Таблица 4 Распространенность коморбидных состояний в ЮКО (n=1400).

\begin{tabular}{|c|c|c|c|c|c|c|c|}
\hline $\begin{array}{l}\text { ХнИЗ } \\
(\mathrm{n}=1009)\end{array}$ & $\mathrm{A} \Gamma$ & СД & $\begin{array}{l}\text { Ожирение } \\
\text { (ИМТ } \geq 30 \text { ) }\end{array}$ & ХБП (СКФ $\leq 60)$ & $\begin{array}{l}\text { Анемия } \\
(\text { Нв }<100)\end{array}$ & ХОБЛ & Всего \\
\hline АГ (464: 45.9\%) & & $60(12,9 \%)$ & $162(34,9 \%)$ & $12(2,6 \%)$ & $13(2,8 \%)$ & $26(5,6 \%)$ & $273(58.8 \%)$ \\
\hline СД (83:8.2\%) & $60(72,3 \%)$ & & $18(21.7 \%)$ & $0(0,0 \%)$ & $2(2,4 \%)$ & $3(3,6 \%)$ & $83(100 \%)$ \\
\hline $\begin{array}{l}\text { Ожирение } \\
\text { (ИМТ } \geq 30) \\
(342: 33.9 \%)\end{array}$ & $162(47,4 \%)$ & $18(5.3 \%)$ & & $9(2,6 \%)$ & $9(2,6 \%)$ & $8(2,3 \%)$ & $206(60.2 \%)$ \\
\hline $\begin{array}{l}\text { ХБП (СКФ } \leq 60) \\
(24: 2.4 \%)\end{array}$ & $12(50,0 \%)$ & $0(0,0 \%)$ & $9(37,5 \%)$ & & $3(12,5 \%)$ & $0(0,0 \%)$ & $24(100 \%)$ \\
\hline $\begin{array}{l}\text { Анемия } \\
(\text { Нв<100) } \\
(50: 4.9 \%)\end{array}$ & $13(26,0 \%)$ & $2(4,0 \%)$ & $9(18,0 \%)$ & $3(6,0 \%)$ & & $0(0,0 \%)$ & 27 (54\%) \\
\hline ХОБЛ (46:4.6\%) & $26(56,5 \%)$ & $3(6,5 \%)$ & $8(17,4 \%)$ & $0(0,0 \%)$ & $0(0,0 \%)$ & & 37 (80.4\%) \\
\hline Всего: & 273 & 83 & 206 & 24 & 27 & 37 & $650(64.4 \%)$ \\
\hline
\end{tabular}

Из данных таблицы 4 следует, что 64.4\% (650 из 1009 с ХНИЗ), включенных в исследование лиц имели коморбидность по двум заболеваниям. При этом наиболее распространенным заболеванием была АГ (45.9\%: 464 из 1009). Наименее распространенным - ХБП (2.4\%: 24 из 1009).

Среди 464 лиц с АГ 58.8\% имели сочетание с другими ХНИЗ. Самым часто встречающимся коморбидным состоянием являлось сочетание АГ и ожирения (34.9\%).
Количество лиц с СД- 83 (8.2\%). При этом все имели сочетание с другими ХНИЗ (100\%). Самым распространенным из них было наличие у больных СД и АГ (72.3\%: 60 из 83). «Ожирение» (ИМТ $\geq 30$ ) выявлялось у 342 лиц, из них 60.2\% (206 из 342) имели коморбидность по двум ХНИЗ. Наиболее частым сочетанием отмечалось сочетание ожирения и АГ (47.4\%: 162 из 342). Наименее частым - ожирение и ХОБЛ (2.3\%: 8 из 342). Среди 24 лиц с ХБП все имели коморбидность 
по двум ХНИЗ (100\%). Анемия встречалась у 4.9\% лиц (у 50 из 1009). При этом 54\% из них имели также сочетание с другими ХНИЗ. Самым распространенным сочетанием было сочетание анемии и АГ $(26 \%)$. В то время как лиц с анемией и хронической обструктивной болезнью легких (ХОБЛ) не выявлено. ХОБЛ диагностировалась у 4.6\% лиц (46 из 1009). У 80.4\% из них (у 37 из 46) имелось сочетание с другими ХНИЗ. Однако у данной категории лиц в основном отмечалась АГ (56.5\%:26 из 46) и небольшое количество лиц с СД (6.5\%: 3 из 46) и ожирением (17.4\%:8 из 46).

Сочетание 3 -х заболеваний диагностировано у $6.7 \%$ лиц (68 из 1009 с ХНИЗ в данном регионе). При этом наиболее частым коморбидным состоянием было наличие у одного пациента СД, АГ и ожирения (5.3\%: у 54 из 1009 с ХНИЗ в целом).

\section{Обсуждение}

В результате исследования эпидемиологической ситуации по Южно-Казахстанской области получена неоднородность распространения поведенческих и биомедицинских факторов риска развития ХНИЗ. При этом самыми распространенными факторами риска ХНИЗ являлись неправильное питание (недостаточное употребление овощей и фруктов) (52.8\%), гиподинамия (51.7\%), повышенная масса тела $(61.5 \%)$ и абдоминальное ожирение $(67.9 \%)$, что согласуется с литературными данными $[7,17,18]$.

В целом по региону число пациентов, имевших сочетание 2-х ХНИЗ, равнялось $48.2 \%$, а 3-х ХНИЗ - 6.7\%. В то время как по данным, полученными Cassell A. и соавт. в исследовании, проведенном в Англии, общее количество пациентов с коморбидными состояниями было всего $27.2 \%$ [18]. Однако по данным других, российских авторов частота коморбидности составляла 94,2\% [9] и наиболее распространенной была также комбинация из двух и трех нозологий.

Наиболее часто встречаемым заболеванием являлась АГ (45.9\% случаев), что согласуется с литературными данными, где отмечено, что АГ относится к самым частым компонентам коморбидности в практике любого врача [19-22]. При этом в терапевтической практике АГ имеет место в $90 \%$ случаев всех возможных сочетаний заболеваний. В нашей выборке $58.8 \%$ пациентов с АГ имели сочетания с другими ХНИЗ. При этом самыми частыми были: АГ и ожирение (34.9\%), АГ и СД (12.9\%).

К другим заболеваниям по данным литературы, входящим в самые частые коморбидные сочетания, принадлежит СД [23-25]. На сегодняшний день СД приобрел максимальную распространенность. К 2030 г., по данным экспертов ВО3, число больных с данной патологией в мире возрастет до 552 млн, свыше 90\% составят больные СД 2-го типа [25]. В нашей исследуемой выборке пациентов с СД было всего 8.2\% (83 из 1009 с ХНИЗ в целом). Однако 100\% из них имели сочетание с другими ХНИЗ. При этом наиболее часто СД ассоциировался с АГ (72.3\%) и с ожирением $(21.7 \%)$, что частично согласуется с имеющимися литературными данными, где указано, что в структуре коморбидности у пациентов с СД на долю АГ приходится 80\%, на долю ожирения $-70 \%[8,24]$.

Хотелось бы добавить, что у $56.5 \%$ пациентов с ХОБЛ нашей выборки выявлялась АГ. Доказано, что в развитых странах ХОБЛ и сердечно-сосудистые заболевания (СС3) являются ведущими причинами смертности и летальности, и в последнее время клиническая значимость таких коморбидных состояний возрастает [26].

У $50 \%$ пациентов с ХБП нашей выборки диагностировалась АГ, что практически совпадает с данными Liam G. и соавт. [21]. При этом в литературе показано, что численность популяции пациентов с почечными нарушениями в настоящее время увеличивается в основном за счет вторичного повреждения почек в рамках СС3: $\mathrm{AГ}$, атеросклероза, ишемической болезни сердца, хронической сердечной недостаточности и фибрилляции предсердий [27].

\section{Выводы}

1. Наиболее распространенными факторами риска хронических неинфекционных заболеваний среди лиц, включенных в исследование в Южно-Казахстанской области, являлись неправильное питание (недостаточное употребление овощей и фруктов), ожирение, гиподинамия.

2. Частота встречаемости хронических неинфекционных заболеваний в целом по Южно-Казахстанской области составила 72.1\%; при этом самым распространенным заболеванием была артериальная гипертензия.

3. Наиболее часто встречающееся коморбидное состояние по двум ХНИЗ - сочетание сахарного диабета и артериальной гипертензии, наименее встречающееся сочетание - ожирение с хроническими болезнями легких.

Disclosures: There is no conflict of interest for all authors.

\section{Литература}

1. Review of social determinants and the health divide in the WHO European regions: final report. Copenhagen: WHO; 2013.188.

2. Global action plan for the prevention and control of noncommunicable diseases 2013-2020. Geneva: WHO; 2013. 102.

3. Wilkinson R., Marmot M. Social determinants of health. The solid facts (2nd Ed). Geneva: WHO; 2003. 32.

4. Statisticheskij sbornik Republic of Kazakhstan in 2016 [in Russian]. Astana; 2017. 144.

5. State program of public health development "Densaulyk" for the period 2016-2020. Order of President of RK from 01.02.2010.№922. [In Russian]. https://kaznmu.kz/rus/wp-content/uploads/2016/03/densaulyk_2016-2020

6. Katsaga A, Kulzhanov M, Karanikolos M, Rechel B. Kazakhstan Health system review. Health Systems in Transition. 2012; 14(4):1154.

7. Oganov R.G., Denisov I.N., Simanenkov V.I., Bakulin I.G., Bakulina N.V., Boldueva S.A. et al. Comorbidities in practice. Clinical guidelines [in Russian]. Cardiovask. Therapy and Prevention. 2017; 16(6):5-56.

8. Fortin M., Bravo G., Hudon C., Vanasse A., Lapointe L. Prevalence of multimorbidity among adults seen in family practice. Ann Fam Med. 2005; 3(3):223-228 https://doi.org/10.1370/afm.272

9. Vertkin A.L., Skotnikov A.S. Comorbidity [in Russian]. Lechashyi vrach. 2013; 6:61-67.

10. Methodics calculation of standart coefficients of birth and mortality [in Russian]. Agency of statistics RK; 2012. 346. 
11. Perk J., De Backer G., Gohlke H., Graham I., Reiner Z., Albus C. et etc. European Guidelines on cardiovascular disease prevention in clinical practice (version 2012): The Fifth Joint Task Force of the European Society of Cardiology and Other Societies on Cardiovascular Disease Prevention in Clinical Practice (constituted by representatives of nine societies and by invited experts). Eur. Heart J.2012; 33:1635-1701 https://doi.org/10.1093/eurheartj/ehs092

12. American Diabetes Association. Standards of medical care in diabetes. Diabetes Care. 2015; 38 (1):1-S93.

13. Alberti K.G., Eckel R.H., Grundy S.M., Zimmet P.Z., Cleeman J.I, Donato K.A. et etc. Harmonizing the Metabolic Syndrome A Joint Interim Statement of the International Diabetes Federation Task Force on Epidemiology and Prevention; National Heart, Lung, and Blood Institute; American Heart Association; World Heart Federation; International Atherosclerosis Society; and International Association for the Study of Obesity. Circulation. 2009; 120:1640-1645. https://doi.org/10.1161/CIRCULATIONAHA.109.192644

14. Shvarts V.Ya. Inflammation of adipose tissue (part 4). Obesity-new infection disease? (review). [in Russian]. Problems of endocrinology. 2011; 5:63-71.

15. Mancia G., Fagard R., Narkiewicz K., Redon J., Zanchetti A., Bohm M et etc. ESH/ESC Guidelines for the management of arterial hypertension: The Task Force for the management of arterial hypertension of the European Society of Hypertension (ESH) and of the European Society of Cardiology (ESC). J. Hypertens. 2013; 31:1281-1357. https://doi.org/10.1097/01.hjh.0000431740.32696.cc

16. Bruce S.G., Riediger N.D., Zacharias J.M., Young T.K. Obesity and obesity-related comorbidities in a Canadian First Nation population. Prev. Chronic Dis. 2011; 8(1): A03.

17. Kukharchuk V.V. Arterial'naya gipertoniya, narusheniya lipidnogo obmena i ateroskleroz. V kn.: Rukovodstvo po arterial'noy gipertonii [Arterial hypertension, lipid disorders and atherosclerosis. In: Guide to an arterial hypertension]. Pod red. Chazova E.I., Chazovoy I.E. [in Russian]. Moscow: Media Medika; 2005. 289-299.

18. Cassell A., Edwards D., Harshfield A., Rhodes K., Brimicombe J., Pavne R., Griffin S. The epidemiology of multimorbidity in primary care: a retrospective cohort study. Br. J. Gen. Pract. 2018; 68(669):e245-e251. https://doi.org/10.3399/bjgp18X695465

19. Van den Akker M., Buntinx F., Metsemakers J., Roos S., Knottnerus J.A. Multimorbidity in general practice: prevalence, incidence, and determinants of co-occurring chronic and recurrent diseases. J. Clin Epidemiol. 1998; 51(5): 367-375. https://doi.org/10.1016/S08954356(97)00306-5

20. Jadad A.R., To M.J., Emara M., Jones J. Consideration of Multiple Chronic diseases in randomized controlled trials. JAMA. 2011 ; 306 (24):2670-2672. https://doi.org/10.1001/jama.2011.1886

21. Liam G., Reddan D., Newell J., Hinde J., Dinneen S.F., Murphy A.W. Multimorbidity and risk among patients with established cardiovascular disease: a cohort study. Br. J. Gen Pract. 2008; 58(552):488-494. https://doi.org/10.3399/bjgp08X319459

22. Caughey G. E., Vitry A. I., Gilbert A. L., Roughead E. E. Prevalence of comorbidity of chronic diseases in Australia. BMC Public Health. 2008; 8:221. https://doi.org/10.1186/1471-2458-8-221

23. Schellevis F. G., Velden J., Lisdonk E., Eiik J.T., Weel C. Comorbidity of chronic diseases in general practice. J. Clin. Epidemiol. 1993; 46(5): 469-473. https://doi.org/10.1016/0895-4356(93)90024-U

24. Gijsen R., Hoeymans N., Schellevis F.G., Ruwaard D., Satariano W.A. Causes and consequences of comorbidity: a review. J. Clinical Epidemiology. 2001; 54(7): 661-674. https://doi.org/10.1016/S0895-4356(00)00363-2

25. Dedov I.I. Diabetes mellitus - a dangerous treat to the mankind [in Russian]. Vestnik RAMS. 2012;1(67):7-13.

26. Rabe K.F., Hurd S., Anzueto A., Barnes P.J., Buist S.A., Calverley P. et etc. Global strategy for the diagnosis, management, and prevention of chronic obstructive pulmonary disease: Gold executive summary. Amer.J.Respir. Crit. Care Med.2007; 176(6):532-555. https://doi. org/10.1164/rccm.200703-456SO

27. Sarnak M.J., Levey A.S., Schoolwerth A.C., Coresh J., Culleton B., Hamm L.L. et etc. Kidney disease as a risk factor for development of cardiovascular disease: a statement from the American Heart Association Councils on Kidney in Cardiovascular Disease, High Blood Pressure Research, Clinical Cardiology, and Epidemiology and Prevention. Hypertension. 2003; 42(5): 1050-1065. https://doi. org/10.1161/01.HYP.0000102971.85504.7c

How to cite this article: Saule Urazalina, Aisulu Mussagalieva, Assel Issabekova, Kulzida Koshumbaeva, Bagdat Akhit. Risk factors of chronic noncommunicable diseases comorbidity in South-Kazakhstan region [in Russian]. J Clin Med Kaz. 2019; 1(51):50-55 